Research Article

\title{
Seismic Earth Pressures of Retaining Wall from Large Shaking Table Tests
}

\author{
Changwei Yang, Jian Jing Zhang, Qu Honglue, Bi Junwei, and Liu Feicheng
}

School of Civil Engineering, Key Laboratory of Transportation Tunnel Engineering, Ministry of Education, Southwest Jiaotong University, Chengdu 610031, China

Correspondence should be addressed to Jian Jing Zhang; zhangzhangjianjing@163.com

Received 25 March 2014; Revised 6 June 2014; Accepted 12 June 2014

Academic Editor: Zhaohui Li

Copyright (c) 2015 Changwei Yang et al. This is an open access article distributed under the Creative Commons Attribution License, which permits unrestricted use, distribution, and reproduction in any medium, provided the original work is properly cited.

To ascertain seismic response of retaining wall in the Wenchuan earthquake, large shaking table tests are performed and an acceleration record is acted in 3 directions. In the tests, acceleration time history recorded at Wolong station in the Wenchuan earthquake is used to excite the model wall. Results from the tests show that the location of dynamic resultant earth pressure is $0.35-0.49 \mathrm{H}$ from toe of the wall for road shoulder retaining wall on rock foundation, $0.33-0.42 \mathrm{H}$ for embankment retaining wall on rock foundation, and $0.46-0.77 \mathrm{H}$ for road shoulder retaining wall on soil foundation. Besides, dynamic earth pressure increases with the increase of ground shaking from $0.1 \mathrm{~g}$ to $0.9 \mathrm{~g}$ and the relationship is nonlinear. The distribution is closed to for PGA less than $0.4 \mathrm{~g}$ but larger for PGA larger than and equal to $0.4 \mathrm{~g}$, especially on the soil foundation. After the comparison of measured earth pressures and theoretical results by pseudodynamic method and pseudostatic method, results of the former are consistent with those of the shaking table test, but results of the latter method are smaller than measured.

\section{Introduction}

The Wenchuan earthquake seriously damaged retaining structures of highway and railway in the disaster areas, which not only brings direct economic losses, but also delays the process of rescue and relief. To support the postdisaster reconstruction and complement the code for seismic design of retaining structures, Zhang et al. [1] carried out a number of field survey and analyses and mainly focused on the seismic damages of retaining structures. Results from the field survey show that the number of damaged gravity retaining walls is up to $97.1 \%$ of all damaged retaining walls. The result stipulates us to carry out seismic performance of gravity walls. Besides, estimation of the seismic earth pressure is an important topic of research for the safe design of retaining wall in the seismic zone. It is a common practice to the seismic accelerations in both horizontal and vertical directions in terms of equivalent static forces, called pseudostatic accelerations. Using the pseudostatic approach, several researchers have developed different methods to determine the seismic earth pressure on a rigid retaining wall due to earthquake loading starting from the pioneering works by Okabe [2] and Mononobe [3], commonly known as Mononobe-Okabe method [4] based on the pseudostatic approach, which gives the linear earth pressure distribution in a very approximate way irrespective of static and seismic conditions. Kumar [5] had determined the seismic passive earth pressure coefficients for sands using limit equilibrium method. Dewaiker and Halkude [6] have proposed a pseudostatic numerical analysis of seismic active and passive thrust on retaining wall, using Kotter's equation. Kumar and Chitikela obtained the seismic passive earth pressure coefficients using method of characteristics. Madhav and Kameswara Rao [7], Choudhury et al. [8], Choudhury [9], and Subba Rao and Choudhury [10] have adopted limit equilibrium for determining individually the seismic passive earth pressure coefficients corresponding to unit weight, surcharge, and cohesion components. Choudhury and Singh [11] have determined active earth pressure coefficients under static and seismic conditions using modified Culmann method. However, all the above methods are based on pseudostatic method of analysis, which does not consider the time effect of the applied earthquake load and the effect of shear and primary waves passing through the soil media. To overcome these drawbacks, the analytical method based on 
pseudodynamic approach as given by Steedman and Zeng [12] and modified by Choudhury and Nimbalker $[13,14]$ is used for the present analysis for calculation of seismic passive and active earth pressure.

Steedman and Zeng [12] considered in their analysis a vertical rigid retaining wall supporting a particular value of soil friction angle and a particular value of seismic horizontal acceleration ( $k_{h g}$, where $g$ is the acceleration due to gravity) only. Again they have considered the effect of horizontal seismic acceleration due to vertically propagating shear waves through the backfill behind retaining wall. In an improvement over this method, Choudhury and Nimbalkar [14] have incorporated effect of vertical seismic acceleration due to vertically propagating primary waves through the backfill soil. Again, they have studied the effect of various parameters such as wall friction angle, soil friction angle, shear wave velocity, primary wave velocity, and both the horizontal and vertical seismic accelerations on the seismic active earth pressure behind a rigid retaining wall by the pseudodynamic method. Choudhury and Nimbalker [13] have extended this modified work for estimation of seismic passive earth pressure.

In the pseudodynamic method, vertically propagating shear and primary waves through the backfill generate vibrations in horizontal and vertical directions, respectively. These horizontal and vertical vibrations correspond to horizontal and vertical time dependent seismic inertia forces, respectively. Time dependent nature of these seismic inertia forces is considered in the present analysis.

After the pseudodynamic method, the dynamic method which is finite element method and the shaking table test are used to the safe design of retaining wall in the seismic zone $[15,16]$.

In the procedure of the development of pseudostatic method, pseudodynamic method, and dynamic method, achievements have been obtained, but some problems have not been understood, such as the location of resultant earth pressure and relationships between earth pressure and ground shaking intensity. As a result, large shaking table tests are performed in order to effectively help us improve the understanding of characteristics of retaining structures in highway and railway engineering. The reason for performing the large shaking table tests is that the tests are the most direct research approach $[17,18]$.

\section{Shaking Table Tests}

2.1. Shaking Table Test. The tests were performed on a large shaking table with an advanced CNC system, data acquisition, and analysis system in the Nuclear Power Research and Design Institute of China. The shaking table, $6 \mathrm{~m}$ by $6 \mathrm{~m}$, has 6 degrees of freedom; the maximum weight is 60 ton, the maximum horizontal displacement is $\pm 150 \mathrm{~mm}$, and the maximal vertical displacement is $\pm 100 \mathrm{~mm}$. The full-loaded horizontal and vertical maximum acceleration is $1.0 \mathrm{~g}$ and $0.8 \mathrm{~g}$ and the horizontal and vertical maximum acceleration for no loading is $3.0 \mathrm{~g}$ and $2.6 \mathrm{~g}$ with frequency ranges from $0.1 \mathrm{~Hz}$ to $80 \mathrm{~Hz}$. And in the shaking table tests, a 128 channel BBM data acquisition system with a maximum referenced error $\leq 0.5 \%$,

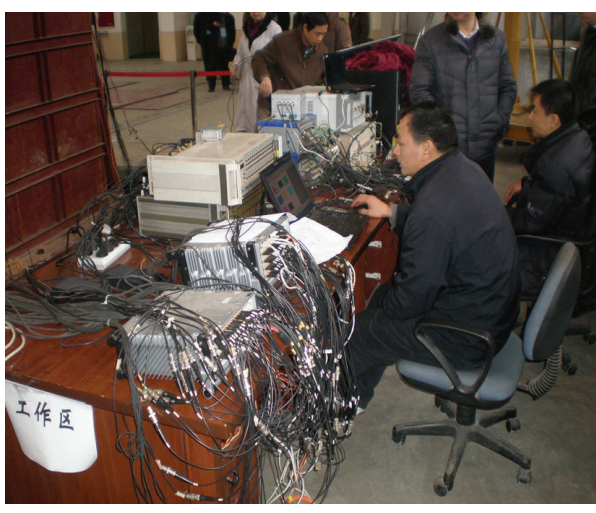

FIGURE 1: Systems of CNC, data acquisition, and analysis.

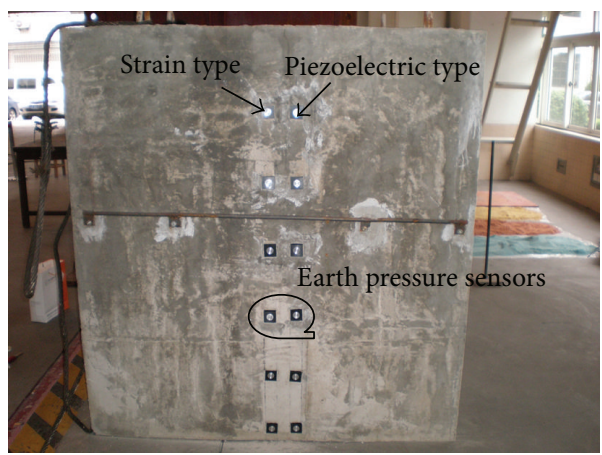

FIGURE 2: Gravity retaining wall model and earth pressure sensor installation diagram.

is used to perform data acquisition, monitoring signal and analysis online synchronously, as shown in Figure 1.

2.2. Retaining Wall Model. In the shaking table tests, three different gravity retaining wall models are constructed in the tests: road shoulder retaining wall on rock foundation, road shoulder retaining wall on soil foundation, and embankment retaining wall on rock foundation.

The internal size of model boxes is $3.7 \mathrm{~m} \times 1.5 \mathrm{~m} \times 2.1 \mathrm{~m}$ and the model box is made of steel frame with steel plate on the bottom. In order to observe movement of the retaining wall and backfill, lateral walls of the steel frame are made of organic glass, and a type of absorbing material is set up on the lateral walls perpendicular to horizontal movement direction for reducing the reflection of seismic wave on the boundary. The height of the model wall is $1.6 \mathrm{~m}$ with a similitude ratio of 6 for modeling a wall with $9.6 \mathrm{~m}$ high and the backfill used in the test is granite sand, as shown in Figure 2. The similitude ratios for density and acceleration are 1, respectively, and similitude relationships of other parameters can be deduced based on Buckingham $\pi$ theorem $[19,20]$. The test model panorama is shown in Figure 3.

Data acquisition includes displacements, accelerations, and total and dynamic earth pressures. The sensor location arrangements are presented in Figure 4, and the sensor installation diagrams of earth pressures and displacements are shown in Figure 2 and Figure 5, respectively. 


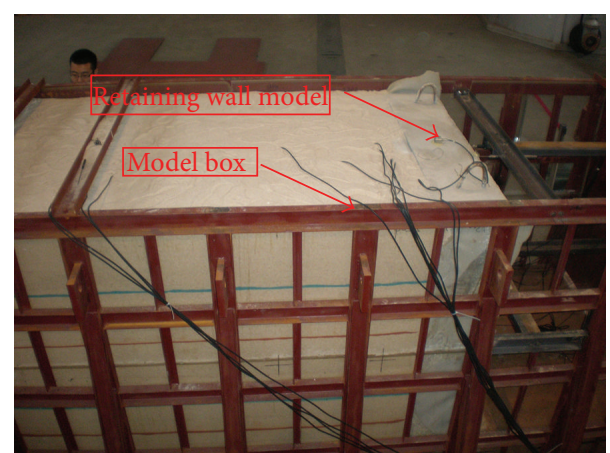

Figure 3: Test model panorama.

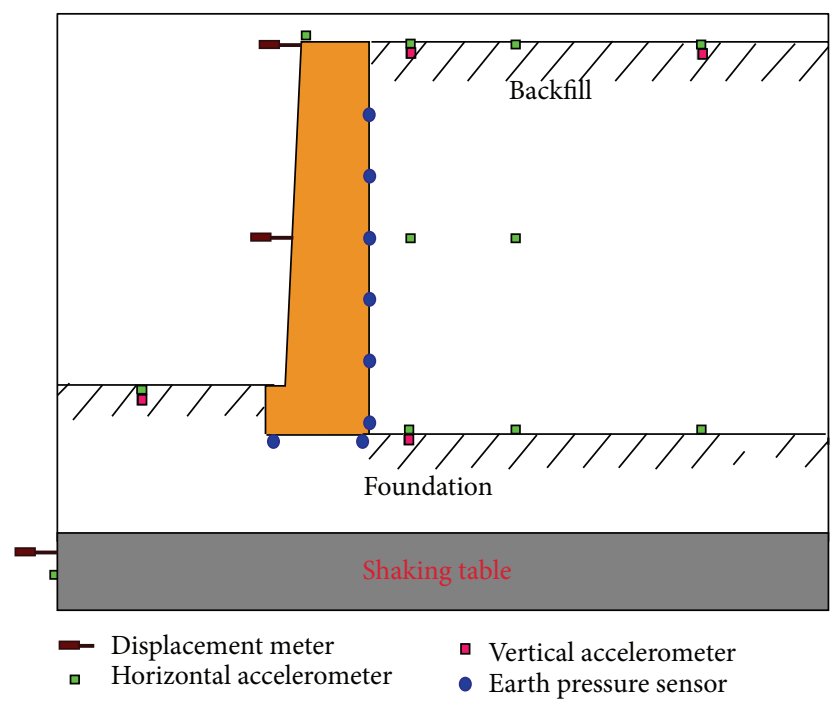

FIGURE 4: The instrument configuration.

2.3. Loading Cases. Horizontal and vertical accelerations recorded at Wolong station in the Wenchuan earthquake are used to excite the model wall, which are scaled in the duration according to the similitude ratio used, as shown in Figure 6. Then the scaled seismic accelerations are scaled again on required amplitudes. The scaled seismic accelerations on duration and amplitude are used as input motions to excite the platform from the horizontal and vertical directions. The loading sequence in the test is white noise, PGA 0.1g, PGA $0.2 \mathrm{~g}$, PGA $0.4 \mathrm{~g}$, PGA $0.7 \mathrm{~g}$, and PGA $0.9 \mathrm{~g}$.

\section{Experimental Result Analyses}

3.1. Earth Pressure Distribution on Backwall. The measured distributions of total and dynamic earth pressures, as shown in Figures 7 and 8, present that the distributions are nonlinear along the wall height and the amplitude of the earth pressures are proportional to the excited seismic peak accelerations $[21,22]$. The dynamic earth pressures are comparatively small for PGA less than $0.4 \mathrm{~g}$ but increase obviously for PGA larger than and equal to $0.4 \mathrm{~g}$. Besides, the rate of earth pressure intensity change is related to geometric position,

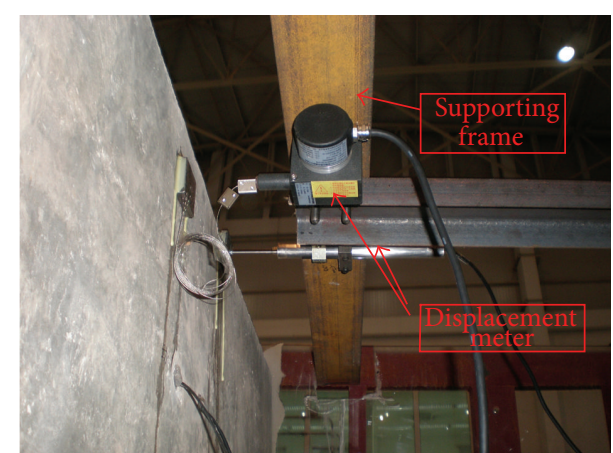

FIgURE 5: Displacement sensor installation diagram.

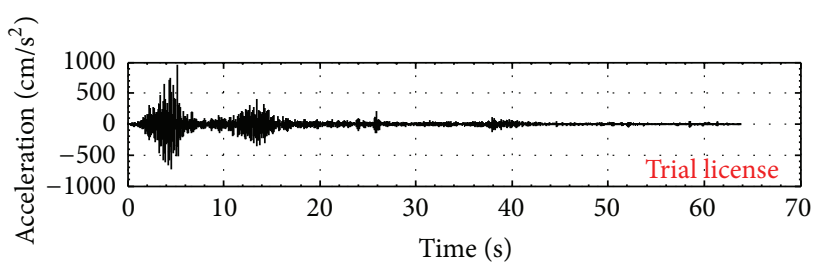

FIGURE 6: Scaled acceleration time history on duration and amplitude.

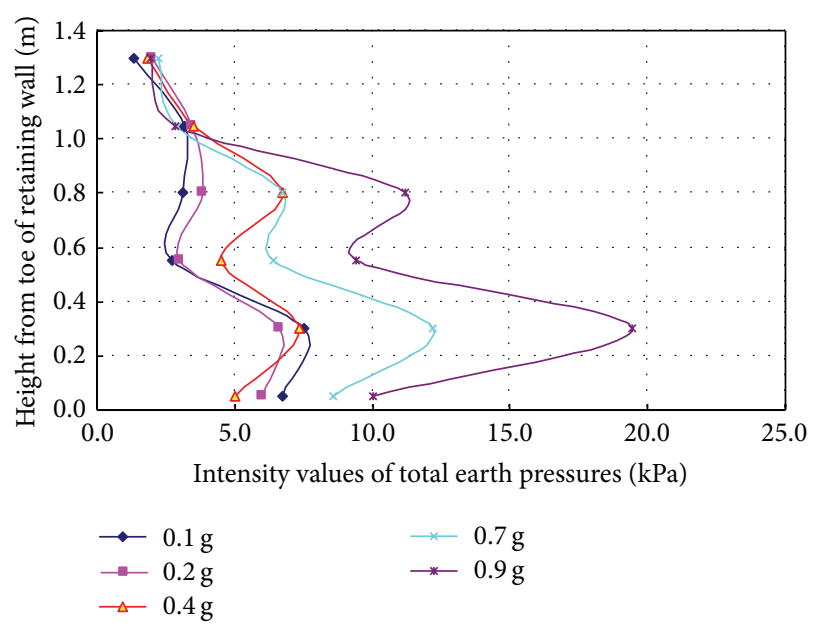

FIgURE 7: The distribution of total earth pressure.

comparatively smaller above $2 / 3 \mathrm{H}$ from toe of the wall but larger below.

3.2. Resultant Earth Pressures on Backwall. Resultant dynamic and total earth pressures are proportional to the excited seismic peak acceleration and increase more obviously with the increase of excited seismic peak accelerations [23], as shown in Figures 9 and 10. The foundation condition of retaining wall is an important influence factor to resultant total and dynamic earth pressure. Compared with retaining walls constructed on rock foundation, the dynamic and total earth pressures of retaining walls on soil foundation are larger. The influence of foundation condition is not obvious when the excited seismic coefficient is low, and the difference 


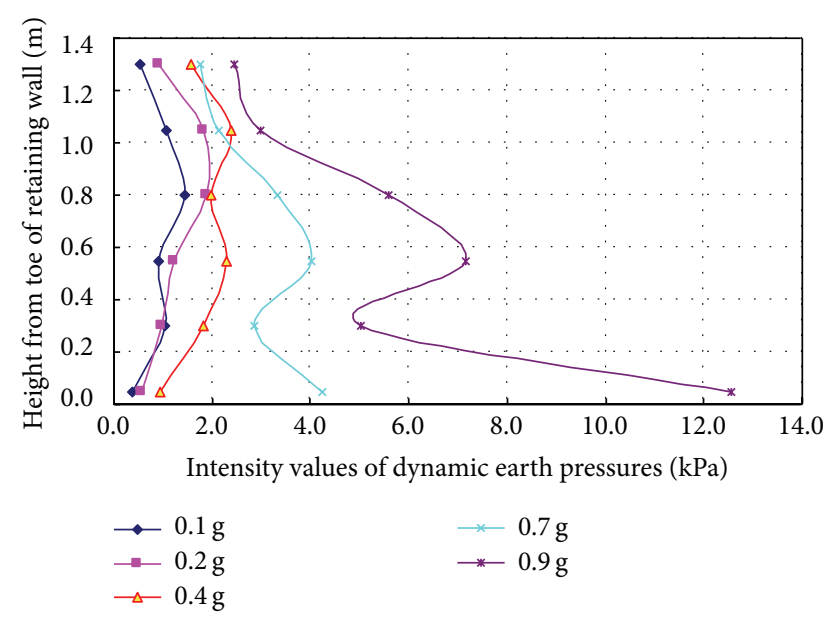

FIGURE 8: The distribution of dynamic earth pressure.

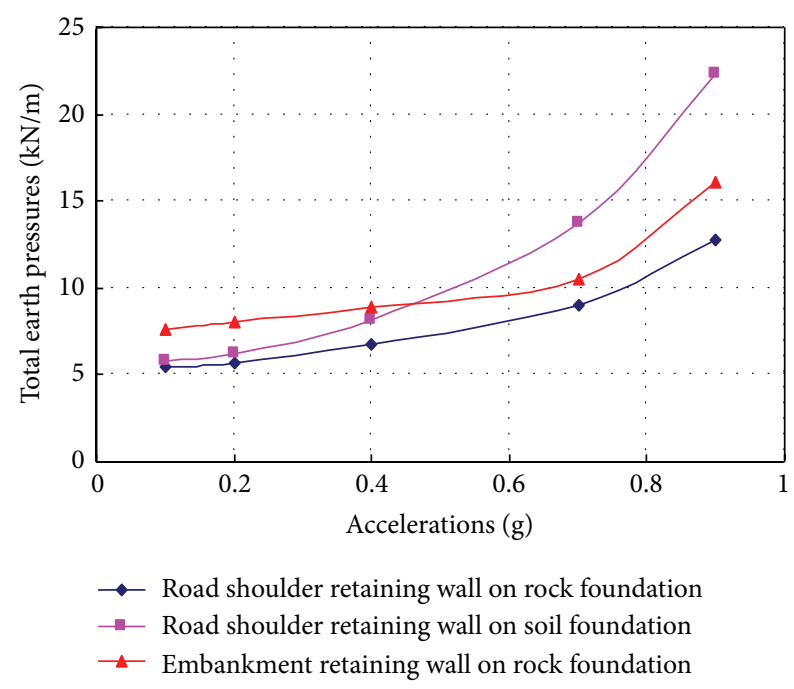

Figure 9: Resultant total earth pressures.

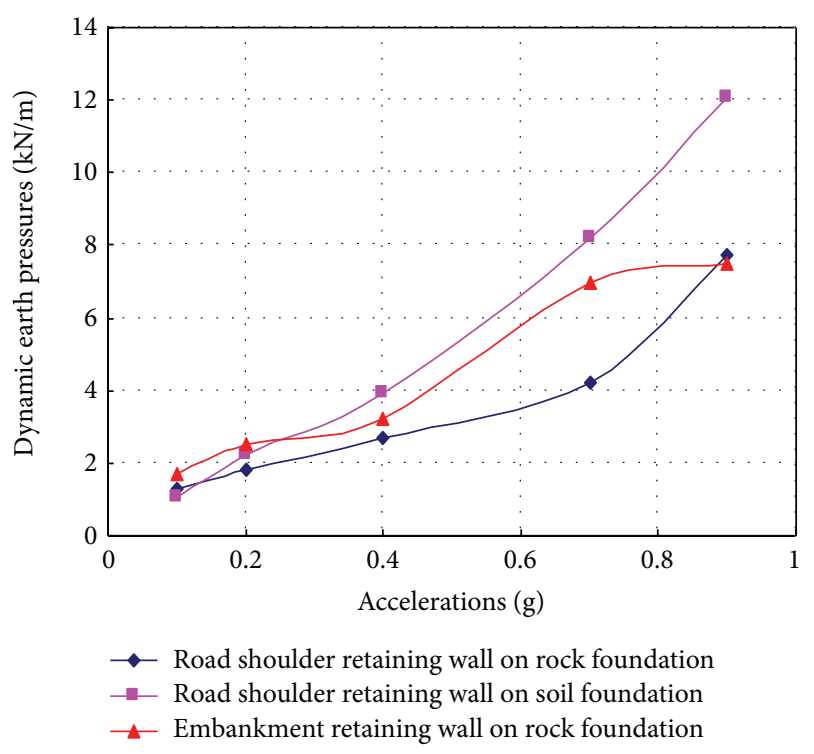

FIGURE 10: Resultant dynamic earth pressures.
TABLE 1: Location of resultant earth pressure of road shoulder retaining wall on rock foundation $(h / H)$.

\begin{tabular}{lcc}
\hline $\begin{array}{l}\text { Seismic } \\
\text { coefficient }\end{array}$ & $\begin{array}{c}\text { Location of resultant } \\
\text { total earth pressure }\end{array}$ & $\begin{array}{c}\text { Location of resultant } \\
\text { dynamic earth } \\
\text { pressure }\end{array}$ \\
\hline 0.1 & 0.34 & 0.46 \\
0.2 & 0.38 & 0.49 \\
0.4 & 0.39 & 0.48 \\
0.7 & 0.34 & 0.4 \\
0.9 & 0.33 & 0.35 \\
\hline
\end{tabular}

${ }^{*} H$ : height of wall; $h$ : height of location of resultant earth pressure from toe of wall.

TABLE 2: Location of resultant earth pressure of embankment retaining wall on rock foundation $(h / H)$.

\begin{tabular}{lcc}
\hline $\begin{array}{l}\text { Seismic } \\
\text { coefficient }\end{array}$ & $\begin{array}{c}\text { Location of resultant } \\
\text { total earth pressure }\end{array}$ & $\begin{array}{c}\text { Location of resultant } \\
\text { dynamic earth } \\
\text { pressure }\end{array}$ \\
\hline 0.1 & 0.44 & 0.38 \\
0.2 & 0.44 & 0.42 \\
0.4 & 0.39 & 0.38 \\
0.7 & 0.35 & 0.33 \\
0.9 & 0.32 & 0.36 \\
\hline
\end{tabular}

of total earth pressure is less than 15\% for PGA less than or equal to $0.3 \mathrm{~g}$ but respectively, $20.56 \%, 52.84 \%$, and $75.02 \%$ for PGA equal to $0.4 \mathrm{~g}, 0.7 \mathrm{~g}$, and $0.9 \mathrm{~g}$. It is clear that the impact of foundation condition becomes greater with the increase of excited seismic peak accelerations. As a result, the influence of foundation on a seismic performance of retaining wall should be considered according to the regions where the retaining wall locates. Comparing to the regions of seismic intensities below 8 degrees if a retaining wall locates, the influence of foundation in the regions with seismic intensities above 8 degrees should be carefully concerned [24].

In addition, the values of total and dynamic earth pressures are relevant to backfill form. The total and dynamic earth pressures of an embankment retaining wall are larger than those of shoulder retaining wall. The differences from the forms of backfill reduced with the increase of excited seismic peak acceleration but should not be ignored, as the embankment earth pressures are still larger.

3.3. Location of Resultant Earth Pressure on Backwall. The measured locations of resultant earth pressures $(h / H)$ are summarized in Tables 1, 2, and 3. Obviously, when the seismic coefficient is low, measured locations of resultant total and dynamic earth pressure are above $0.33 \mathrm{H}$ from the toe of wall. With the increase of seismic coefficient, the locations become close to $0.33 \mathrm{H}$, which is provided by $\mathrm{M}-\mathrm{O}$ formula $[2,3]$. Figure 11 presents the results of the locations of resultant total earth pressures $(h / H)$ with excited seismic coefficients of three different test models, and Figure 12 presents the results of the locations of resultant dynamic earth pressures $(h / H)$ with excited seismic coefficients of three different test models. 
TABLE 3: Location of resultant earth pressure of road shoulder retaining wall on soil foundation $(h / H)$.

\begin{tabular}{lcc}
\hline $\begin{array}{l}\text { Seismic } \\
\text { coefficient }\end{array}$ & $\begin{array}{c}\text { Location of resultant } \\
\text { total earth pressure }\end{array}$ & $\begin{array}{c}\text { Location of resultant } \\
\text { dynamic earth } \\
\text { pressure }\end{array}$ \\
\hline 0.1 & 0.63 & 0.77 \\
0.2 & 0.61 & 0.76 \\
0.4 & 0.55 & 0.64 \\
0.7 & 0.48 & 0.46 \\
0.9 & 0.4 & 0.46 \\
\hline
\end{tabular}

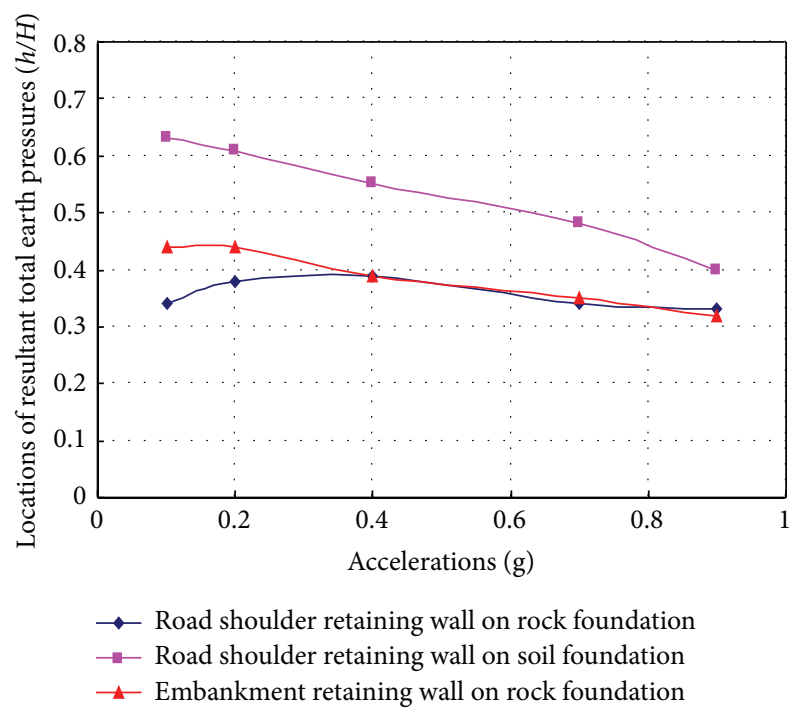

FIgURE 11: Locations of resultant total earth pressures $(h / H)$.

From Figures 11 and 12, we can see that, for a road shoulder retaining wall, the locations of resultant total earth pressure are lower than those of resultant dynamic earth pressure, and the difference gradually reduces with the increase of seismic coefficient [25]. Table 1 shows that the locations are between $0.33 \mathrm{H}$ and $0.39 \mathrm{H}$ for total earth pressures, while they are between $0.35 \mathrm{H}$ and $0.49 \mathrm{H}$ for dynamic earth pressures. For embankment retaining wall, the locations of resultant total and dynamic earth pressures are lower when compared with those for the road shoulder retaining wall, and when seismic coefficient is lower, the locations of resultant total earth pressure are higher than those of resultant dynamic earth pressure. With the increase of seismic coefficient, the locations of resultant total and dynamic earth pressure become close [26]. Table 2 shows that the locations are between $0.32 \mathrm{H}$ and $0.44 \mathrm{H}$ for total earth pressures, while they are between $0.33 \mathrm{H}$ and $0.42 \mathrm{H}$ for dynamic earth pressures.

The foundation conditions of retaining wall have a strong impact on the locations of resultant earth pressure. Normally, the softer the foundation is, the higher the locations are. For the shoulder retaining wall constructed on soil foundation, the resultant locations are between $0.4 \mathrm{H}$ and $0.63 \mathrm{H}$ for total earth pressures, while they are between $0.46 \mathrm{H}$ and $0.77 \mathrm{H}$ for dynamic earth pressures, as shown in Table 3.

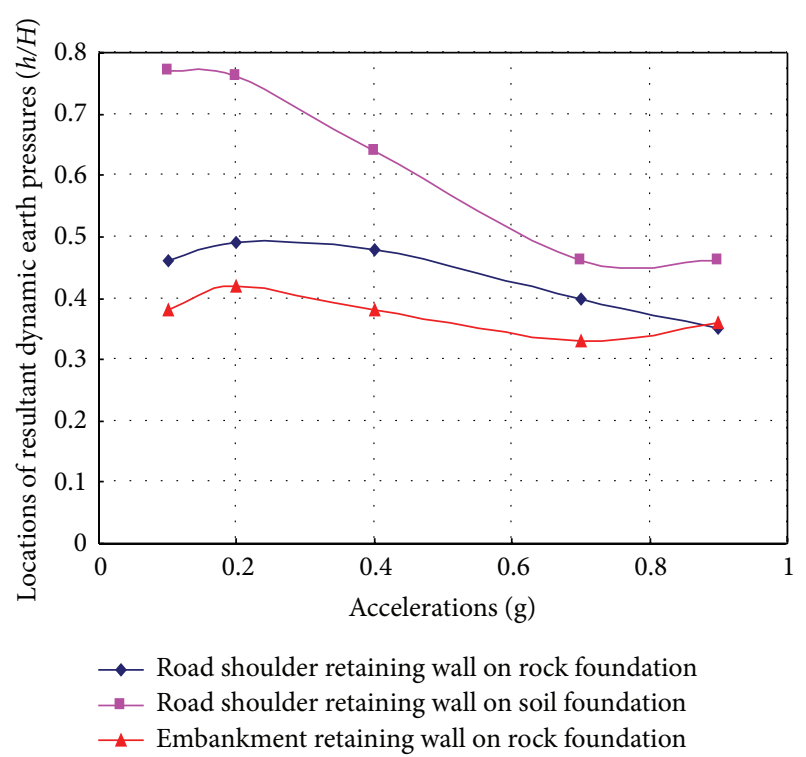

FIGURE 12: Locations of resultant dynamic earth pressures $(h / H)$.

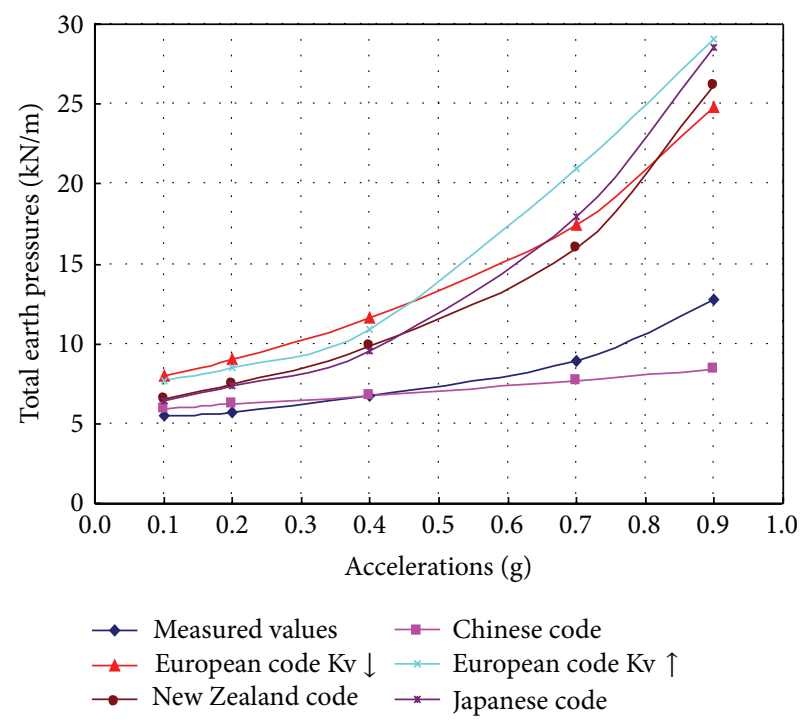

FIGURE 13: Comparison of measured earth pressures and theoretical results by codes for rock foundation.

3.4. Comparison of Measured Earth Pressures and Theoretical Results by Codes. The diagrams of comparison between measured earth pressures and theoretical results by codes on rock and soil foundation, respectively, are shown in Figures 13 and 14.

Figures 13 and 14 show that, for rock foundation, the results by Chinese code are close to the measured earth pressures in the regions of seismic intensities below 8 degrees and smaller in the regions of seismic intensities above 8 degrees, while the results from European, Japanese, and New Zealand codes are conservative, contrast to Chinese code.

For soil foundation, the theoretical method by Chinese code for design of aseismic retaining wall is reasonable in the regions of seismic intensities below 8 degrees but is dangerous 


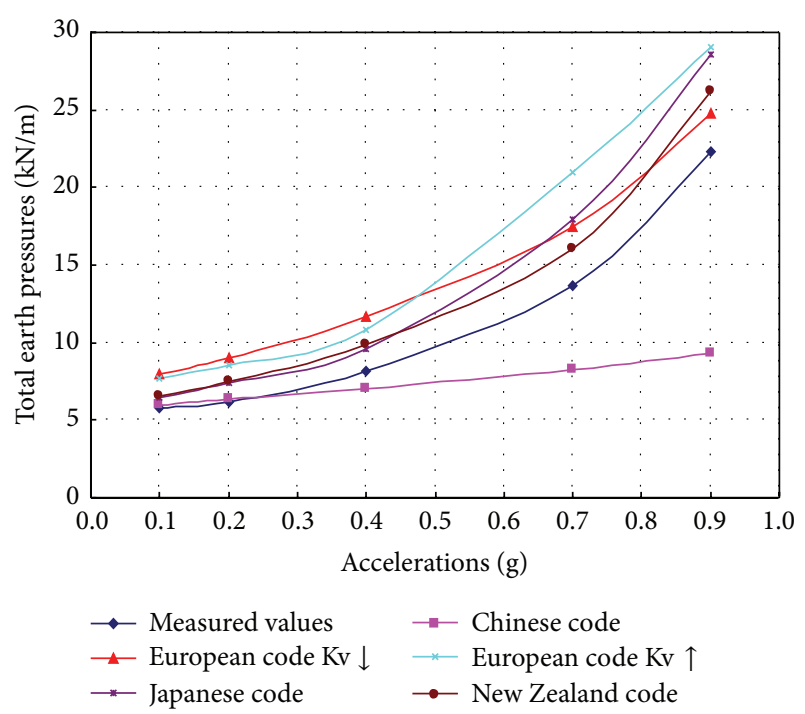

FIGURE 14: Comparison of measured earth pressures and theoretical results by codes for soil foundation.

in the regions of seismic intensities above 8 degrees, as the theoretical results are obviously smaller than measured. Nevertheless, the other theoretical results by the European, Japanese, and New Zealand codes are slightly larger than the measured, and the difference between the codes is slight with seismic acceleration. In contrast to the Chinese code, these foreign codes are comparatively reasonable, and the results from the New Zealand code are closest to the measured ones.

\subsection{Comparison of Measured Earth Pressures and Theoretical} Results by Pseudostatic Method (Mononobe-Okabe Method) and Pseudodynamic Method [27]. In order to make a comparison of measured earth pressures and theoretical results by pseudostatic method and pseudodynamic method, this paper uses the same material parameters, earthquake wave, and the analysis model with the shaking table test for the rock foundation. The results are shown in Figures 15 and 17.

Figures 15, 16, and 17 show that, for the measured earth pressures, the results for the pseudostatic method and the pseudodynamic method are closed to shaking table test; for the total earth pressures and the location of resultant total earth pressures, the results for the pseudodynamic method are obviously closer to the shaking table test than those for pseudostatic method.

Therefore, the results of pseudodynamic method are consistent with those of the shaking table test, but the results of pseudostatic method are smaller than measured.

\section{Conclusions}

(1) The distribution of total and dynamic earth pressure is nonlinear along the backwall. The dynamic earth pressures increase obviously for PGA larger than and equal to $0.4 \mathrm{~g}$. Besides, the earth pressure intensity change speeds are related to geometric position, comparatively smaller above $2 / 3 \mathrm{H}$ from toe of the wall but larger below.

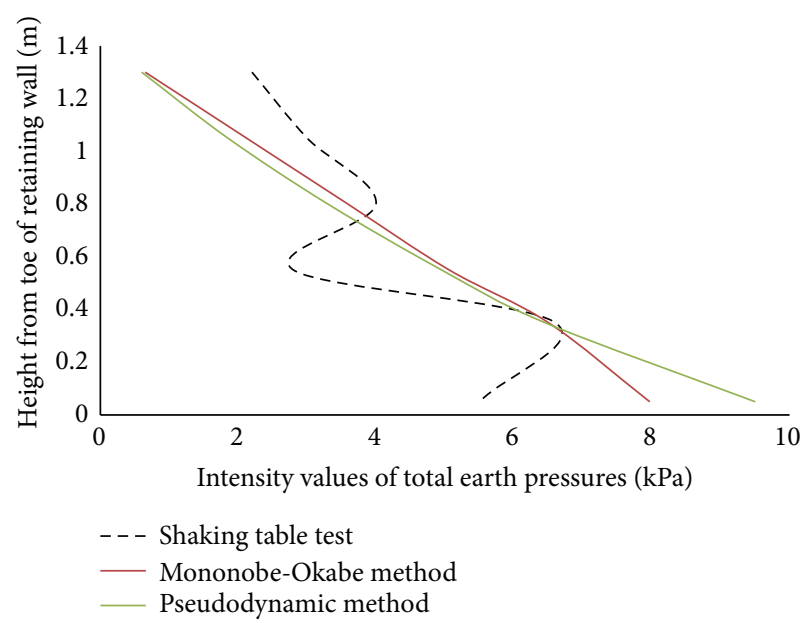

FIGURE 15: Comparison of measured earth pressures and theoretical results by pseudostatic method and pseudodynamic method for rock foundation (PGA of the input seismic wave is $0.4 \mathrm{~g}$ ).

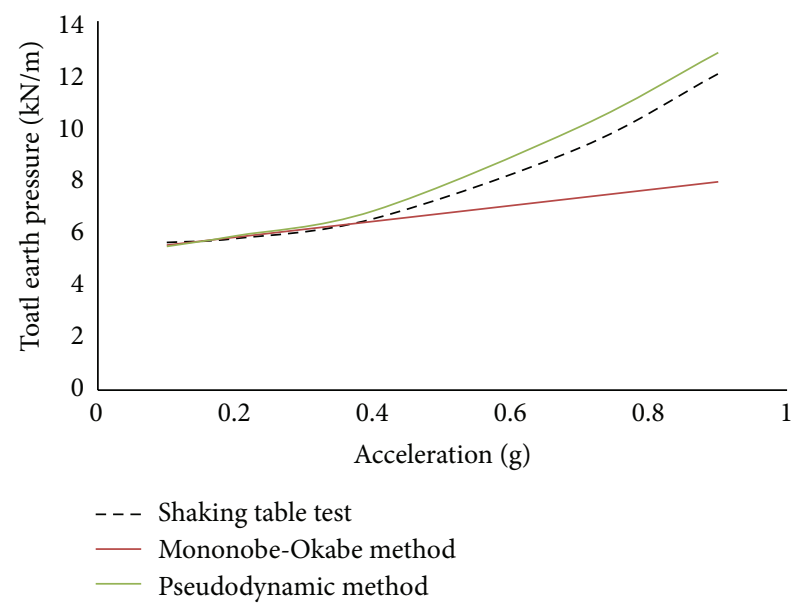

FIGURE 16: Comparison of measured total earth pressures and theoretical results by pseudostatic method and pseudodynamic method for rock foundation.

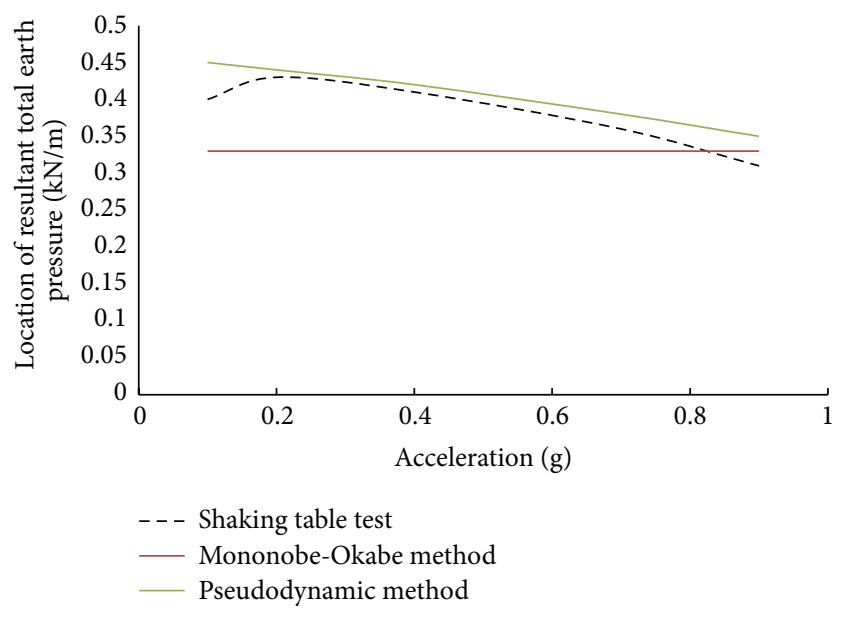

FIGURE 17: Comparison of locations of resultant total earth pressures $(h / H)$ and theoretical results by pseudostatic method and pseudodynamic method for rock foundation. 
(2) Resultant dynamic and total earth pressures grow more obviously along with the increase of seismic accelerations.

Comparing to rock foundation retaining wall, the dynamic and total earth pressures of soil foundation are larger. The foundation influence to design of aseismic retaining wall should be considered according to the regions and in the regions of seismic intensities above 8 degrees it should be carefully concerned.

The values of total and dynamic earth pressures are relevant to backfill form. The earth pressures of retaining wall on embankment are larger than on road shoulder. The influence from the form of backfill becomes less obvious along with seismic acceleration increasing but should not be ignored, as the numerical values are totally greater.

(3) When the seismic coefficient is low, measured locations of resultant total and dynamic earth pressure are above $0.33 \mathrm{H}$ from the toe of wall, which is provided by $\mathrm{M}-\mathrm{O}$ formula. With the rising of seismic coefficient, the locations become close to $0.33 \mathrm{H}$.

For retaining wall on road shoulder, the locations of resultant total earth pressure are lower than those of resultant dynamic earth pressure, and the gaps become closer with seismic coefficient rising. For retaining wall on embankment, the locations of resultant total and dynamic earth pressure are lower comparing to the retaining wall on road shoulder, and when the seismic coefficient is low, the locations of resultant total earth pressure are higher than those of resultant dynamic earth pressure. With the rising of seismic coefficient, the locations of resultant total and dynamic earth pressure become close.

The foundation condition has a strong impact on the locations of resultant earth pressure. At the same time, the softer, the locations higher.

(4) For rock foundation, the theoretical method for design of aseismic retaining wall provided by Chinese code is reasonable in the regions of seismic intensities below 8 degrees and smaller in the regions of seismic intensities above 8 degrees, while the results from those compared codes are too conservative.

For soil foundation, the method by Chinese code is reasonable in the regions of seismic intensities below 8 degrees but is dangerous in the regions of seismic intensities above 8 degrees. In contrast to the Chinese code, these foreign codes are comparatively reasonable, and the results from the New Zealand code are closest to the measured ones.

(5) The results of pseudodynamic are consistent with those of the shaking table test, but the results of pseudostatic method are smaller than measured.

\section{Conflict of Interests}

The authors of this paper do not have any conflict of interests regarding the publication of this paper.

\section{Acknowledgments}

The authors wish to thank Dr. Hongsheng Ma and Bo Xiang for providing help in their field trip and survey. This study is supported in part by NSF of China (Contract no. 51408510), Guangxi Science Foundation, and the Program for Science and Technology.

\section{References}

[1] J. J. Zhang, J. Feng, S. G. Xiao, and C. Q. Liu, "Discussions on two key technical problems for seismic design of retaining structures," Journal of Southwest Jiaotong University, vol. 44, no. 3, pp. 321-326, 2009.

[2] N. Okabe, "General theory on earth pressure and seismic stability of retaining wall and dam," Journal of Japan Society of Civil Engineers, vol. 10, no. 6, pp. 1277-1323, 1924.

[3] N. Mononobe, "Considerations on vertical earthquake motion revelant vibration problems," Journal of Japan Society of Civil Engineerings, vol. 10, no. 5, pp. 1063-1094, 1924.

[4] S. L. Kramer, Geotechnical Earthquake Engineering, Prentice Hall, New Jersey, NJ, USA, 1996.

[5] J. Kumar, "Seismic passive earth pressure coefficients for sands," Canadian Geotechnical Journal, vol. 38, no. 4, pp. 876-881, 2001.

[6] D. M. Dewaikar and S. A. Halkude, "Seismic passive/active thrust on retaining wall-point of application," Soils and Foundations, vol. 42, no. 1, pp. 9-15, 2002.

[7] M. R. Madhav and N. S. V. Kameswara Rao, "Earth pressure under seismic conditions," Soils and Foundations, vol. 9, no. 4, pp. 33-47, 1969.

[8] D. Choudhury, K. S. SubbaRao, and S. Ghosh, "Passive earth pressures distribution under condition," in Proceedings of the 15th International conference of Engineering Mechanics Division, ASCE, New York, NY, USA, June 2002.

[9] D. Choudhury, "Seismic passive resisteance at soil-wall interface," in Proceedings of the 17th ASCE Engineering Mechanics Conference, University of Delaware, Netwark, Del, USA, 2004.

[10] K. S. Subba Rao and D. Choudhury, "Seismic passive earth pressures in soils," Journal of Geotechnical and Geoenvironmental Engineering, vol. 131, no. 1, pp. 131-135, 2005.

[11] D. Choudhury and S. Singh, "New approach for estimation of static and seismic active earth pressure," Geotechnical \& Geological Engineering, vol. 24, no. 1, pp. 117-127, 2006.

[12] R. S. Steedman and X. Zeng, "Centrifuge modeling of the effects of earthquakes on free cantilever walls," in Centrifuge, vol. 91, pp. 425-430, Balkema, Rotterdam, The Netherlands, 1991.

[13] D. Choudhury and S. Nimbalkar, "Seismic passive resistance by pseudo-dynamic method," Geotechnique, vol. 55, no. 9, pp. 699702, 2005.

[14] D. Choudhury and S. S. Nimbalkar, "Pseudo-dynamic approach of seismic active earth pressure behind retaining wall," Geotechnical and Geological Engineering, vol. 24, no. 5, pp. 1103-1113, 2006.

[15] T. Xia, W. Hua, and Z. Wang, "Analysis of seismic active earth pressure of cohesive soil behind inclined retaining wall," World Earthquake Engineering, vol. 26, no. 1, pp. 315-321, 2010.

[16] W. Liyan and L. Hanlong, "Study of seismic active arth pressure acted on gravity wall in backfill sand," China Journal of Highway and Transport, vol. 22, no. 6, pp. 26-33, 2009.

[17] R. Siddharthan, S. Ara, and G. Norris, "Simple rigid plastic model for seismic tilting of rigid walls," Journal of structural engineering New York, N.Y., vol. 118, no. 2, pp. 469-487, 1992.

[18] X. Zeng, "Seismic response of gravity quay walls. I: centrifuge modeling," Journal of Geotechnical and Geoenvironmental Engineering, vol. 124, no. 5, pp. 406-417, 1998. 
[19] M. Celebi, "Seismic responses of two adjacent buildings. II. Interaction," Journal of Structural Engineering, vol. 119, no. 8, pp. 2477-2492, 1993.

[20] H. A. Smith and W.-H. Wu, "Effective optimal structural control of soil-structure interaction systems," Earthquake Engineering \& Structural Dynamics, vol. 26, no. 5, pp. 549-570, 1997.

[21] N. M. Newmark, "Effects of earthquakes on dams and embankments," Geotechnical, vol. 15, no. 2, pp. 59-139, 1965.

[22] Y. Z. Wang, "Distribution of earth pressure on a retaining wall," Geotechnique, vol. 50, no. 1, pp. 83-88, 2000.

[23] R. Richards and D. G. Elms, "Seismic behavior of gravity retaining walls," Journal of Geotechnical Engineering, vol. 105, no. 4, pp. 444-449, 1979.

[24] D. C. Yao, "Retaining wall seismic failure analysis," Engineering Journal of Wuhan University, vol. 36, no. 2, pp. 82-87, 2003.

[25] J. H. Wood, "Earthquake-induced pressures on a rigid wall structure," Bulletin of the New Zealand Society for Earthquake Engineering, vol. 8, no. 3, pp. 86-175, 1975.

[26] X. Zeng and R. S. Steedman, "Rotating block method for seismic displacement of gravity walls," Journal of Geotechnical and Geoenvironmental Engineering, vol. 126, no. 8, pp. 709-717, 2000.

[27] B. Munwar Basha and G. L. Sivakumar Babu, "Reliability assessment of internal stability of reinforced soil structures: a pseudo-dynamic approach," Soil Dynamics and Earthquake Engineering, vol. 30, no. 5, pp. 336-353, 2010. 

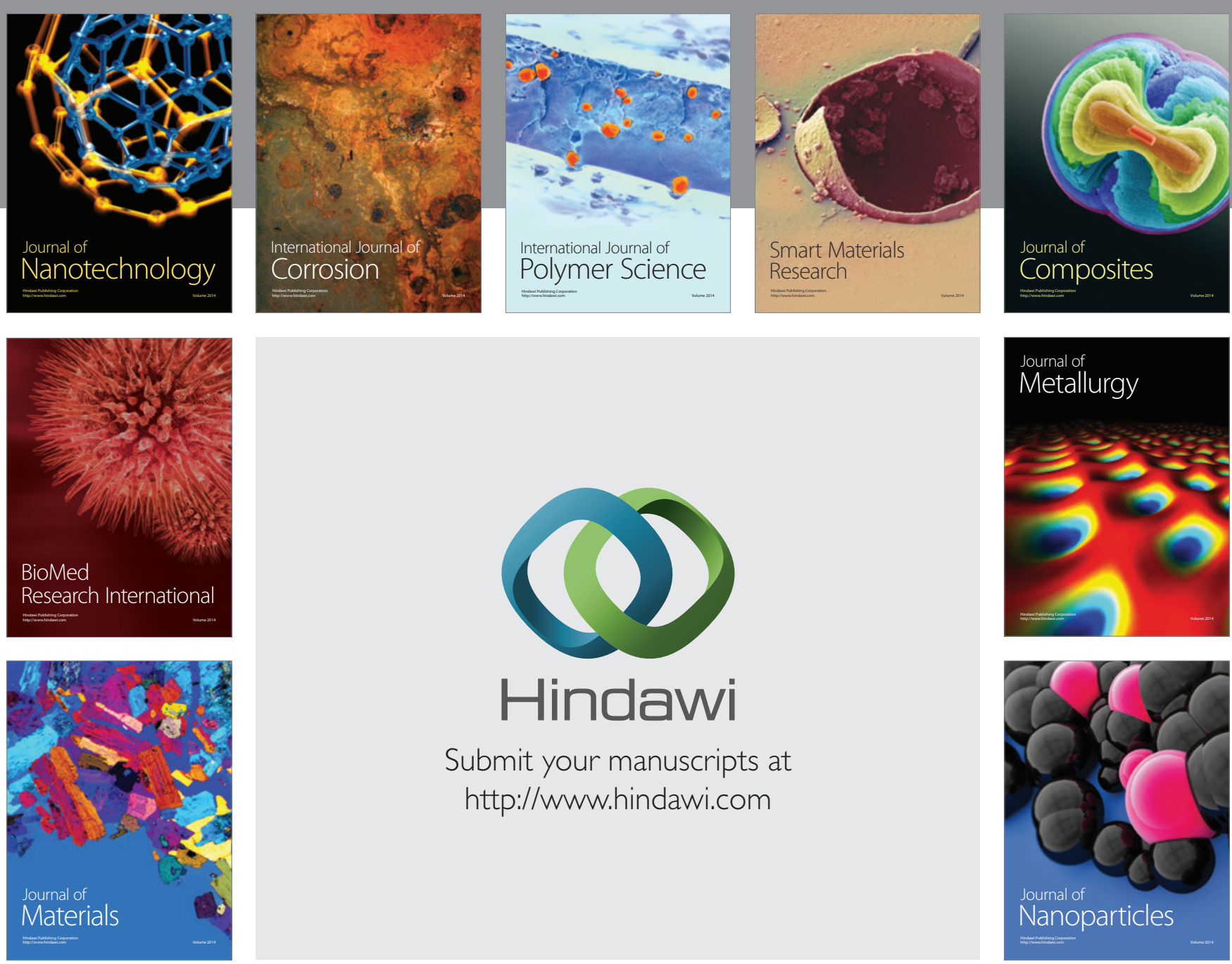

Submit your manuscripts at http://www.hindawi.com
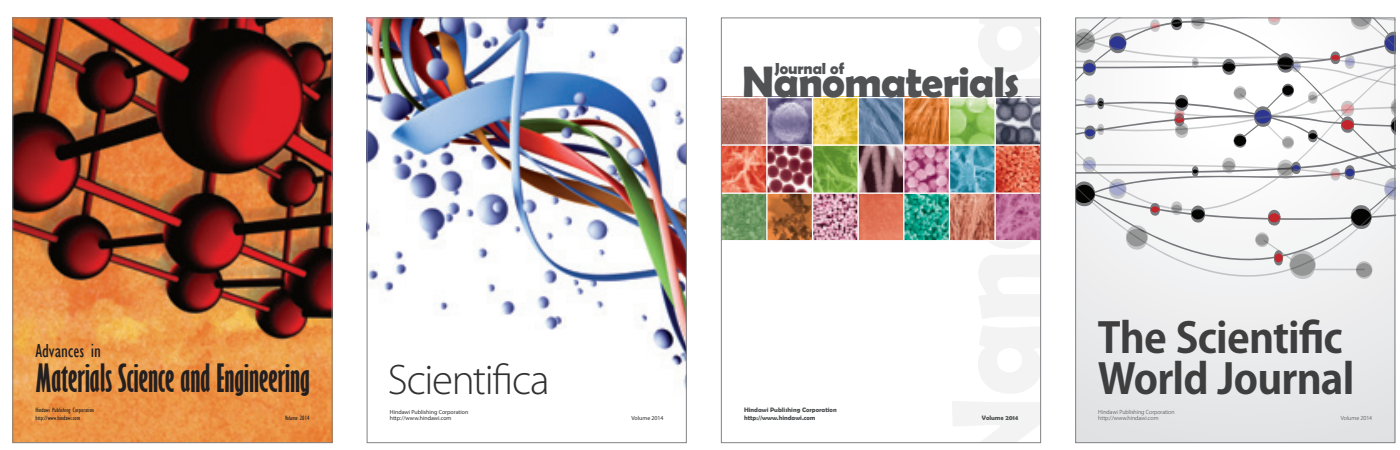

\section{The Scientific World Journal}
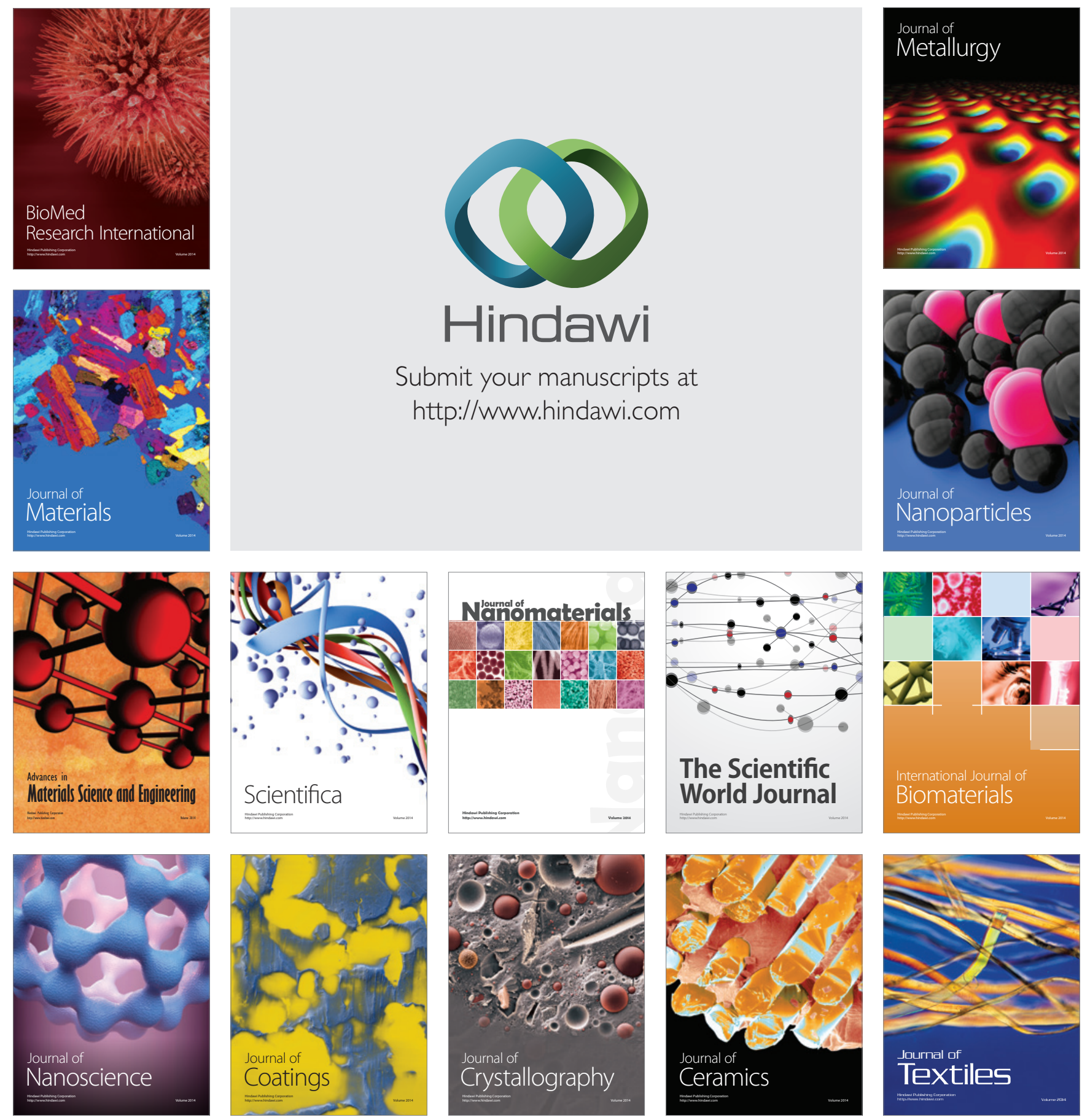